Argonne

ANL-21/44

\title{
Mitigating Phase Unbalance for Distribution Systems with High Penetrations of Solar PV
}

Final Technical Report 


\section{About Argonne National Laboratory}

Argonne is a U.S. Department of Energy laboratory managed by UChicago Argonne, LLC

under contract DE-AC02-06CH11357. The Laboratory's main facility is outside Chicago, at 9700 South Cass Avenue, Argonne, Illinois 60439. For information about Argonne

and its pioneering science and technology programs, see www.anl.gov.

\section{DOCUMENT AVAILABILITY}

Online Access: U.S. Department of Energy (DOE) reports produced after 1991 and a growing number of pre-1991 documents are available free at OSTI.GOV (http://www.osti.gov/), a service of the US Dept. of Energy's Office of Scientific and Technical Information.

Reports not in digital format may be purchased by the public from the National Technical Information Service (NTIS):

U.S. Department of Commerce

National Technical Information Service

5301 Shawnee Rd

Alexandria, VA 22312

www.ntis.gov

Phone: (800) 553-NTIS (6847) or (703) 605-6000

Fax: (703) 605-6900

Email: orders@ntis.gov

Reports not in digital format are available to DOE and DOE contractors from the

Office of Scientific and Technical Information (OSTI):

U.S. Department of Energy

Office of Scientific and Technical Information

P.O. Box 62

Oak Ridge, TN 37831-0062

www.osti.gov

Phone: (865) 576-8401

Fax: (865) 576-5728

Email: reports@osti.gov 


\section{Mitigating Phase Unbalance for Distribution Systems with High Penetrations of Solar PV}

Final Technical Report

\section{Project Team:}

Daniel K. Molzahn (Argonne National Laboratory, Energy Systems Division)

Line A. Roald (University of Wisconsin-Madison, ECE)

Johanna L. Mathieu (University of Michigan, EECS)

Ian A. Hiskens (University of Michigan, EECS)

Dave Pinney (National Rural Electric Cooperative Association)

Bowen Li (Argonne National Laboratory, Energy Systems Division)

Kshitij Girigoudar (University of Wisconsin-Madison, ECE)

Mengqi Yao (University of Michigan, EECS)

Sijia Geng (University of Michigan, EECS)

September 2021 


\begin{tabular}{|l|l|}
\hline a. Federal Agency & Department of Energy \\
\hline b. Award Number & DE-EE00034235 \\
\hline c. Project Title & $\begin{array}{l}\text { Mitigating Phase Unbalance for Distribution } \\
\text { Systems with High Penetrations of Solar PV }\end{array}$ \\
\hline d. Principal Investigator & $\begin{array}{l}\text { Daniel Molzahn } \\
\text { Computational Engineer } \\
\text { dmolzahn@anl.gov }\end{array}$ \\
\hline e. Business Contact & $\begin{array}{l}\text { Judy Janovyak } \\
\text { Financial Business Partner } \\
\text { jjanovyak@anl.gov }\end{array}$ \\
\hline f. Submission Date & March 31, 2020 \\
\hline g. Recipient Organization & Argonne National Laboratory \\
\hline h. Project Period & $\begin{array}{l}\text { Start: October 1, } \\
2018\end{array}$ \\
\hline
\end{tabular}

\section{Acknowledgement:}

This material is based upon work supported by the U.S. Department of Energy's Office of Energy Efficiency and Renewable Energy (EERE) under the Lab Call FY19-21 Award Number 34235.

\section{Executive Summary:}

Distribution system operators have traditionally limited unbalance among phases by maintaining similar loadings on each phase. High penetrations of distributed solar PV continually change the net loading on each phase, resulting in time-varying phase unbalances that can damage three-phase devices such as three-phase motors, violate grid codes, and increase technical losses. This project has developed several control strategies for the reactive power outputs of solar PV inverters in order to mitigate power quality issues related to phase unbalance. These control strategies include a decentralized approach that is solely based on local measurements, distributed and grouped approaches that consider subsets of loads and PV generators, and a centralized approach that leverages measurements from a variety of locations in order to compute optimal reactive power setpoints for each inverter. Variants of the controllers handle challenges relevant to practical implementations, including noisy measurements, delayed communications, and reactive power limits. Moreover, the project developed theory that provides convergence guarantees for systems with multiple interacting controllers as well as "balancibility" certificates that ensure satisfaction of phase unbalance requirements with variable loading. The controllers were integrated with NRECA's Open Modeling Framework (omf.coop) and evaluated using actual distribution system models obtained 
from several NRECA member utilities. Application of the controllers results in significant improvements to phase unbalance in these test cases with decreases from base case levels of over $3 \%$ to under $0.5 \%$, which is within the $2 \%$ IEC phase unbalance standard.

\section{Background:}

Increasing deployments of solar PV generation challenge system operators' ability to maintain power quality in distribution systems. This project has focused on the power quality issue of phase unbalances, which can damage three-phase devices such as large motor loads, violate grid codes, and increase technical losses. Common impacts of phase unbalance in three-phase motors include torque pulsations, increased vibrations and mechanical stresses, larger losses, and motor overheating, resulting in shorter winding insulation lifetimes. Due to these impacts, possible severe consequences include premature motor failures, costly shutdowns, and lost production. Figure 1 below shows the impacts that phase unbalance has on motor losses and the resulting derating factors needed for safe operation [10]. The repair and replacement costs due to phase unbalance problems are significant. For U.S. industries, the cost associated with phase unbalance problems is up to $\$ 28$ billion a year [11].
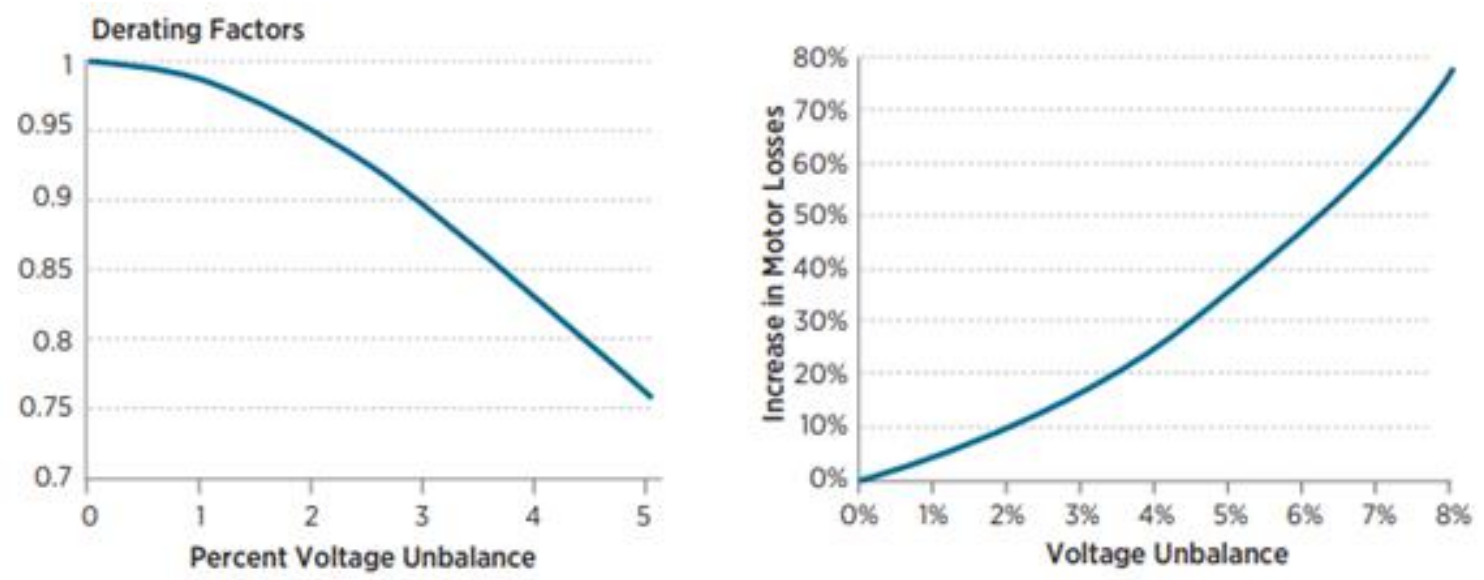

\section{Figure 1: Derating factors of induction motors (left) and the increase in motor losses (right) due to the unbalanced voltage [9].}

Industry typically employs several techniques for mitigating phase unbalances, including using switching to transfer loads among various circuits [12], properly selecting and configuring system components [13], and installing passive reactances that balance nominal load impedances [14]. Power electronic devices are particularly well-suited for correcting time-varying phase unbalances [15], [16]. Existing industrial techniques generally focus on mitigating the unbalances that result from large individual loads. These existing techniques are not well suited to addressing unbalance due to loads or PV inverters that are distributed along a feeder, where the location and magnitude of the unbalance are unknown and vary significantly over time. Moreover, existing industry 
techniques can rely on the installation of new equipment or require slow and laborintensive reconnections of various loads.

Previous research efforts have also proposed alternate techniques for mitigating phase unbalances. A switching strategy is proposed to modify the phase assignment of singlephase PVs in [17], but this method may not scale to systems with large numbers of distributed PVs. Rather than controlling the reactive power from solar PV inverters, some previous techniques adjust real power via undesirable renewable curtailment and use of energy storage [18] or require specialized hardware [19], [20]. Other previous techniques control reactive power, but only consider a centralized formulation and neglect uncertainties [21]-[23] or are formulated to achieve other objectives besides phase unbalance mitigation [24]. In contrast, the controllers developed in this project are more desirable due to the control of only reactive power and more practical due to our tailoring of the various controllers to the available measurement and communication architectures.

\section{Project Objectives:}

Without appropriate control, large-scale deployments of solar PV generation may exacerbate power quality problems with respect to phase unbalance, leading to increased losses, voltage problems, equipment failures, and violation of grid codes. These issues have the potential to limit the deployment of large quantities of solar PV generators. This project developed and tested controllers that enable operation of distribution systems with high penetrations of solar PV generation while maintaining acceptable levels of phase unbalance. The control strategies developed in this project enable solar PV generators to contribute to mitigating phase unbalance via low-cost reactive power adjustments. Specifically, the project has developed multiple types of controllers that minimize voltage unbalance over a prescribed group of loads and PV generators. These controllers include:

- A centralized controller that relies on feeder-wide communication and different levels of measurement availability.

- A decentralized controller that relies on local measurements and no bus-to-bus communication.

- Distributed and grouped controllers appropriate for intermediate levels of communication and coordination.

Relative comparisons of the levels of communication and complexity associated with each controller are given in Figure 2 on the following page. 


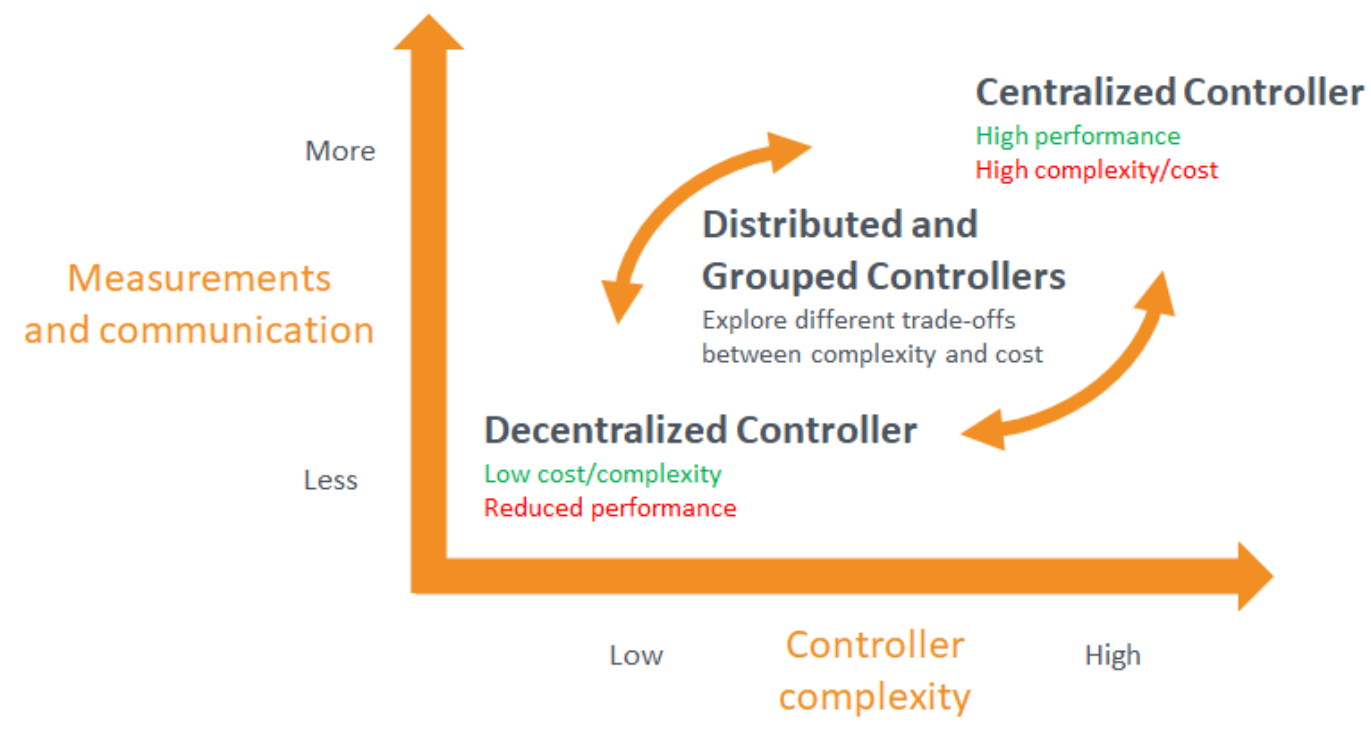

Figure 2: Conceptual comparisons of the developed controllers.

Using simulations of the controllers on actual NRECA distribution system models in the NRECA Open Modeling Framework (omf.coop), this project has analyzed trade-offs among these controllers and their impacts on other system objectives, such as maintaining acceptable voltage magnitudes. Moreover, the project has produced advancements in related theory, including analytical comparisons of different phase unbalance definitions, conditions which guarantee convergence of the decentralized controller, and "balancibility" conditions which ensure robust satisfaction of specified phase unbalance requirements for a range of operating conditions. Practical considerations were also considered and addressed in the controller development, including reactive power limitations, time-varying load demands and renewable generator outputs, communication delays and errors, and measurement noise.

The project completed all of the planned project tasks:

Task 1: Development of testing and evaluation procedures. Work for this task identified the most relevant metrics as well as several real test cases from NRECA member co-ops, which were used to evaluate the controllers' performance.

Task 2: Controller formulation and testing. Work for this task developed the mathematical formulations and computational implementations of the centralized, decentralized, distributed, and grouped controllers. The initial implementations were improved in order to be tractable for realistic systems.

Task 3: Performance comparisons. Work for this task applied the controller implementations to both standard distribution system test cases as well as real systems obtained from NRECA member co-ops. Results demonstrating and analyzing the controllers' performance were accepted for publication in peer-reviewed journals and conferences and also distributed to industry via NRECA outreach to member co-ops. 
The project achieved all four of the planned milestones.

Milestone 1: Identify appropriate NRECA feeder test cases. Three NRECA feeders were obtained and modified to simulate a range of solar PV scenarios.

Milestone 2: Formulate centralized, decentralized, distributed, and grouped controllers. These controllers and several variants were developed and documented.

Milestone 3: Implement and apply controllers to test cases. The controllers were implemented in software and integrated into NRECA's Open Modeling Framework.

Milestone 4: Test and compare the controllers on NRECA systems. The controllers were applied to the NRECA test cases from Milestone 1. Analyses of their performance were published in peer-reviewed journals and conferences and also distributed to industry via NRECA outreach to member co-ops.

\section{Summary of Economic Impacts of the Controllers Developed in this Project:}

As discussed previously, voltage unbalance on distribution systems causes significant damage to three-phase motors. Each $0.2 \%$ increase in unbalance reduces motor lifetime by approximately one year [10, Table 5-3].

In tests on three representative NRECA utility circuits, the distributed controllers developed in this project lower voltage unbalance for each load on the system by $59 \%$ or more. ${ }^{1}$ The controllers are estimated to extend the lifetime of the average three phasemotor in our test set by nine years and hence reduce motor replacement costs by approximately $\$ 2,300$ per substation. For a detailed discussion of the analysis, please see the subsection of this report titled "Application to NRECA test cases".

On the national level, we estimate total potential savings of $\$ 115$ million. Approximately $400 \%$ more benefit could be realized by adding storage charged by solar to extend the controls into times with no solar PV output. ${ }^{2}$ Voltage unbalance also increases the technical losses in distribution systems and decreases motor efficiency, but these savings are much smaller than the improvement in motor life.

Existing methods for mitigating voltage unbalance require manual labor and specialized equipment to switch loads between phases. In contrast, our control techniques can be done in software remotely and automatically, making the implementation costs negligible.

\footnotetext{
${ }^{1}$ Averaged over the distributed controller results for all test circuits. Centralized control numbers are closer to $95 \%$.

${ }^{2}$ Motor lifetime impacts were calculated based on the results in [10]. We assume a $70 \%$ penetration rate of solar PV as a function of distribution load, $20 \%$ solar capacity factor, motor costs of $\$ 67 / \mathrm{kW}$, and 50,000 US distribution substations. Improvements due to storage were calculated by projecting the benefits to a $100 \%$ capacity factor scenario.
} 


\section{Project Results and Discussion:}

To summarize the project results, this section describes the controllers that were created by the team, presents their performance when applied to several real NRECA test cases, and discusses theoretical developments associated with the controllers.

The controllers are organized according to their formulation:

1. Optimization formulation: Controller behavior is determined by solving an optimization problem. Reference [4] details the optimization formulation used by the centralized controller in this project.

2. Steinmetz formulation: Controller behavior corresponds to the Steinmetz circuit design [25], [26]. The goal of Steinmetz circuit design is to inject an appropriate amount of reactive power into each phase to make unbalanced three-phase loads appear as balanced three-phase loads. In addition, we constrain the total compensating reactive power injections to be zero in order to avoid significant changes in the feeder's voltage profile. Reference [7] details the Steinmetz formulations developed by the project team for the decentralized, distributed, and grouped controllers.

Throughout this report, we refer to the buses with critical three-phase devices, such as three-phase motors, as "critical buses".

\section{Centralized Controller (Optimization Formulation):}

The centralized controller was formulated via optimization problems with objective functions and constraints that consider voltage unbalance in a three-phase distribution system. One purpose of the centralized controller is to generate optimal solutions to which we could benchmark the solutions of the other controllers. As discussed below, the centralized controller may not be practically or economically realizable due to its needs for significant data (parameters, real-time states) and a pervasive communication network, along with its high computational burden.

Developing the centralized controller required that we select one of several existing definitions of voltage unbalance. Table 1 on the following page summarizes the various voltage unbalance definitions used by organizations such as IEC, NEMA, and IEEE in their power quality standards. In [2], the project team developed mathematical analyses that analytically characterize the relationships among these definitions. In [4], the project team also analyzed how different phase unbalance definitions impact the outcomes achieved with the centralized controller.

The centralized controller was implemented in Julia with the distribution network modelled in the "phase frame". The three-phase distribution network model included voltage regulators, transformers, ZIP loads, and distribution lines. The controller implementation was benchmarked against the results from GridLAB-D models. This included developing 
a parser to convert all the required data from GridLAB-D .glm files to a format readable by the Julia code. A detailed formulation of the centralized controller including the distribution system modelling is available in [4].

Since the centralized controller is flexible enough to facilitate minimization of various objective functions, the project team conducted further investigations to evaluate the effects of minimizing voltage unbalance on other important power quality metrics such as network losses and substation power factor. Flexibility in selecting an objective function also allows for focusing the phase unbalance mitigation improvements on a subset of critical buses. Associated results are described later in this report as well as in [4].

\begin{tabular}{|c|c|c|}
\hline Definition & Standard & Formula \\
\hline $\begin{array}{l}\text { Voltage Unbalance } \\
\text { Factor (VUF) }\end{array}$ & IEC & $\begin{aligned} V U F[\%] & =\frac{\left|\mathbf{V}_{n}\right|}{\left|\mathbf{V}_{p}\right|} \times 100 \\
\text { where } \mathbf{V}_{p} & =\frac{\mathbf{V}_{a}+\mathbf{a} \cdot \mathbf{V}_{b}+\mathbf{a}^{2} \cdot \mathbf{V}_{c}}{3} \\
\mathbf{V}_{n} & =\frac{\mathbf{V}_{a}+\mathbf{a}^{2} \cdot \mathbf{V}_{b}+\mathbf{a} \cdot \mathbf{V}_{c}}{3}\end{aligned}$ \\
\hline $\begin{array}{l}\text { Line Voltage Unbalance } \\
\text { Rate (LVUR) }\end{array}$ & NEMA & $\begin{array}{c}\text { LVUR }[\%]=\frac{\Delta V_{L}^{\max }}{V_{L}^{a v g}} \times 100, \\
\text { where } V_{L}^{a v g}=\frac{V_{a b}+V_{b c}+V_{c a}}{3}, \\
\Delta V_{L}^{\max }=\max \left\{\left|V_{a b}-V_{L}^{a v g}\right|,\left|V_{b c}-V_{L}^{a v g}\right|,\left|V_{c a}-V_{L}^{a v g}\right|\right\} .\end{array}$ \\
\hline $\begin{array}{l}\text { Phase Voltage } \\
\text { Unbalance Rate (PVUR) }\end{array}$ & IEEE & $\begin{array}{c}\text { LVUR }[\%]=\frac{\Delta V_{L}^{\max }}{V_{L}^{a v g}} \times 100, \\
\text { where } V_{L}^{a v g}=\frac{V_{a b}+V_{b c}+V_{c a}}{3}, \\
\Delta V_{L}^{\max }=\max \left\{\left|V_{a b}-V_{L}^{a v g}\right|,\left|V_{b c}-V_{L}^{a v g}\right|,\left|V_{c a}-V_{L}^{a v g}\right|\right\} .\end{array}$ \\
\hline
\end{tabular}

Table 1: Voltage unbalance definitions.

The centralized controller performance was tested on taxonomic feeders ranging in size from 30 to 1000 buses. To scale the implementation to larger systems, the project team developed an approach that uses a fixed-point interpretation of the nonlinear AC power flow equations [22]. Figure 3 illustrates the flow diagram of the fixed-point approach. This strategy resulted in a computationally efficient implementation of the centralized controller with convergence time around 15-20 mins for large test cases ( $>1800$ buses).

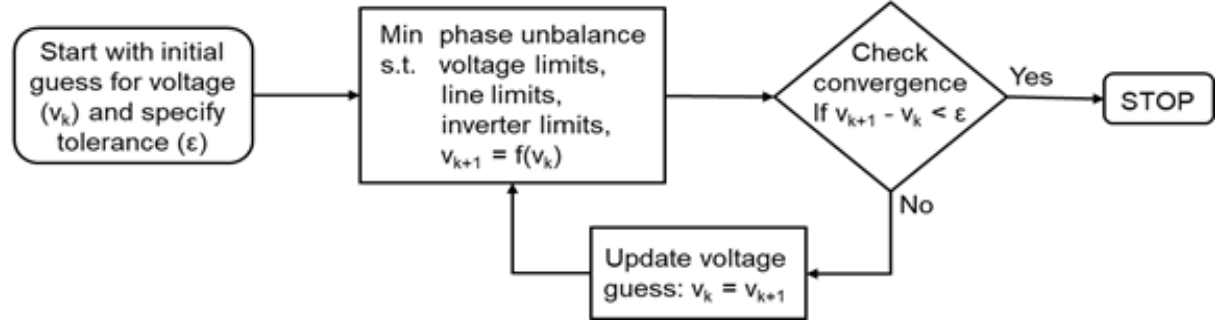

Figure 3: Block diagram of centralized controller using a fixed-point approach. 


\section{Decentralized controller (Steinmetz Formulation):}

Contrasting with the centralized controller developed in this project which considers distribution feeders with extensive communication infrastructures, the project team also developed a decentralized controller applicable to systems where no bus-to-bus communication is available. Each bus measures the three-phase complex voltage and apparent power flowing into that bus in order to compute the required reactive power injections, but only injects reactive power into the phases to which distributed PVs at that bus are connected. For example, if all PV at that bus are connected to Phase A, they only inject reactive power into Phase A.

\section{Distributed controller (Steinmetz Formulation):}

The distributed controller is applicable to systems for which a simple communication network is available. The controller measures both the three-phase complex voltage of the critical bus and the apparent power flowing into the critical bus and then uses Steinmetz circuit design to compute three-phase reactive power injections. The controller commands downstream PV systems to collectively provide the required reactive power injections. The commands are sent to each PV system in proportion to its apparent power capacity. PV systems inject as commanded, up to their reactive power limits, and do not communicate their actions back to the controller (i.e., one-way communication).

\section{Grouped controller (Steinmetz Formulation):}

Unlike the distributed controller which coordinates all the downstream PV systems as one group, we also partition the feeder into multiple groups. For the grouped controller, local communication/coordination exists within groups but not between groups. This strategy produces solutions between those from the decentralized and distributed controllers.

\section{Controller Evaluations and Comparisons:}

We evaluated the performance of all controllers on a number of test cases. This report first details results for the taxonomic 'R1-12.47-1' feeder (617 buses and 1196 triplex buses) as an illustrative example. This system's one-line diagram is shown in Figure 4 on the following page. PV systems were added to 598 single family residences, with 265 , 150 , and 183 of those systems connected to phases $A, B$, and $C$, respectively. We assume that they operate at unity power factor when uncontrolled. The total active power generation is $1773 \mathrm{~kW}$, which is around $21.5 \%$ of the system load. For all time-varying solar PV profiles in this report, we used one-minute solar irradiance data from the National Renewable Energy Laboratory's Measurement and Instrumentation Data Center. ${ }^{3}$ Further details regarding this system and an expanded discussion of the results for this and other test cases are available in several publications produced by the project team [5], [6], [9].

${ }^{3}$ https://midcdmz.nrel.gov/ 
For our test case, we select bus 359 as the critical bus. The initial VUF at this bus is $3.06 \%$, which is in violation of the $2 \%$ IEC standard. We next describe the application of each controller to this test case. Additional illustrative results using an NRECA test case are shown in the following sections.

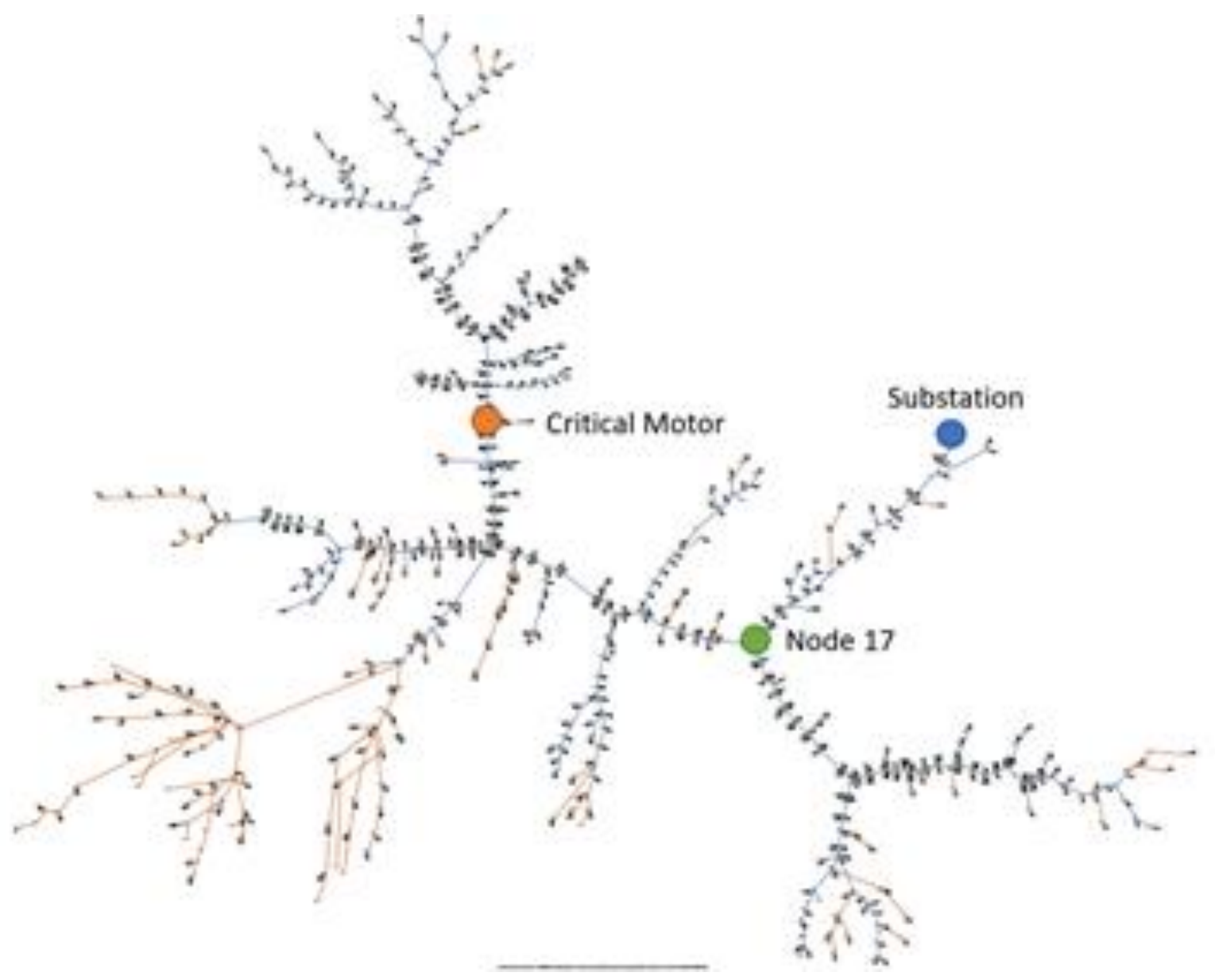

Figure 4: One-line diagram of the R1-12.47-1 feeder. ${ }^{4}$

Since the critical bus chosen for this test case is far from the substation, we found that directly implementing the distributed controller at the critical bus cannot significantly reduce the unbalance of the critical bus. This is because i) the number of controllable downstream PV systems is small and ii) upstream unbalance will still make the voltage at the critical bus unbalanced even if we are able to balance the downstream loading. Therefore, with the aim of improving the unbalance of bus 359, we apply our distributed controller to an upstream bus (bus 17), i.e., we measure the voltage and current at bus 17 and compute the required reactive power injections based on Steinmetz circuit design to balance bus 17 using PV systems downstream of bus 17. This reduces the unbalance

${ }^{4}$ GridLAB-D Taxonomy Feeder Graphs. Available: http://emac.berkeley.edu/gridlabd/taxonomy graphs/ 
at nearly all buses, including bus 359. For the grouped controller, all PV systems are divided into six groups based on their geographic area.

Figure 5 on the next page shows the VUF at all three-phase buses in the feeder. The blue solid line shows the VUF at before applying control; the red solid line shows the VUF after applying the distributed controller at bus 17 (the VUF at bus 359 decreases from $\mathbf{3 . 0 6 \%}$ to $1.25 \%$ ); the yellow solid line shows the VUF after applying the decentralized controller (the VUF at bus 359 decreases from $3.06 \%$ to $1.70 \%$ ); the purple solid line shows the VUF after applying the grouped controller (the VUF at bus 359 decreases from $3.06 \%$ to $1.34 \%$ ); and the green solid line shows the VUF after applying the centralized controller (the VUF is reduced from $3.06 \%$ to $\mathbf{0 . 1 5 \%}$ ). Observe that all controllers successfully reduce the phase unbalance at the critical bus to satisfy the $2 \%$ IEC standard. Also notice that the decentralized controller achieves the least unbalance improvement. The distributed and grouped controllers can further mitigate the unbalance if we consider the case where an appropriate communication infrastructure exists. As expected, the performance of the grouped controller is between that of the decentralized and the distributed controllers. The centralized controller has the best performance in mitigating phase unbalance; however, this controller requires a detailed system model and more computational time is needed in order to provide the optimal reactive power injections.

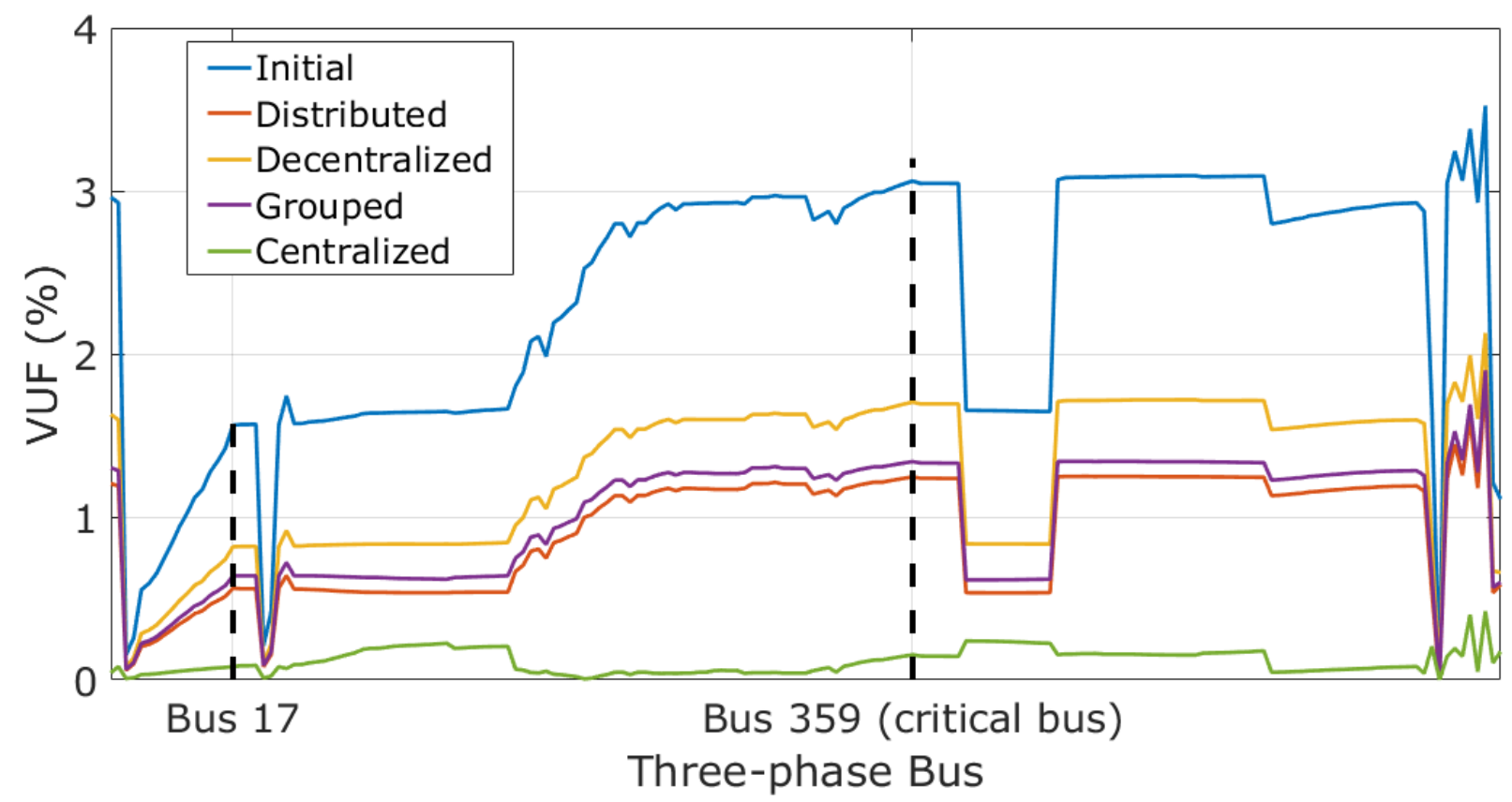

Figure 5: VUF at all three-phase buses before and after use of the distributed, decentralized, grouped, and centralized controllers.

As discussed previously, the centralized controller provides the flexibility to explicitly consider different objectives. To illustrate this, Figures 6 and 7 on the following page show 
the VUF voltage unbalance at all three-phase nodes for the R1-12.47-1 taxonomic feeder, with and without the centralized controller (red and blue lines, respectively). Figure 6 below shows the controller performance when minimizing unbalance at only one bus (bus 17), while Figure 7 depicts the controller performance when minimizing the average unbalance across all three-phase nodes in the system. For both cases, the centralized controller is able to significantly reduce the voltage unbalance in the system.

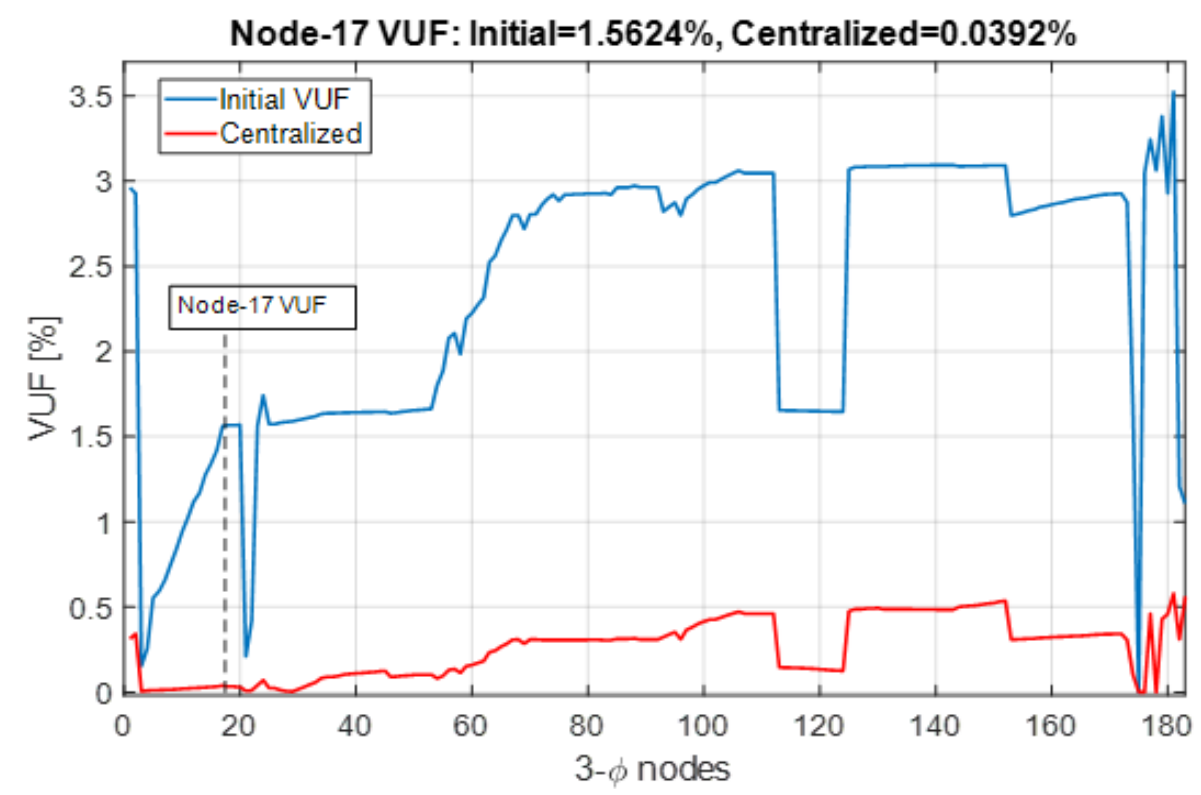

Figure 6: Minimize phase unbalance at one critical bus.

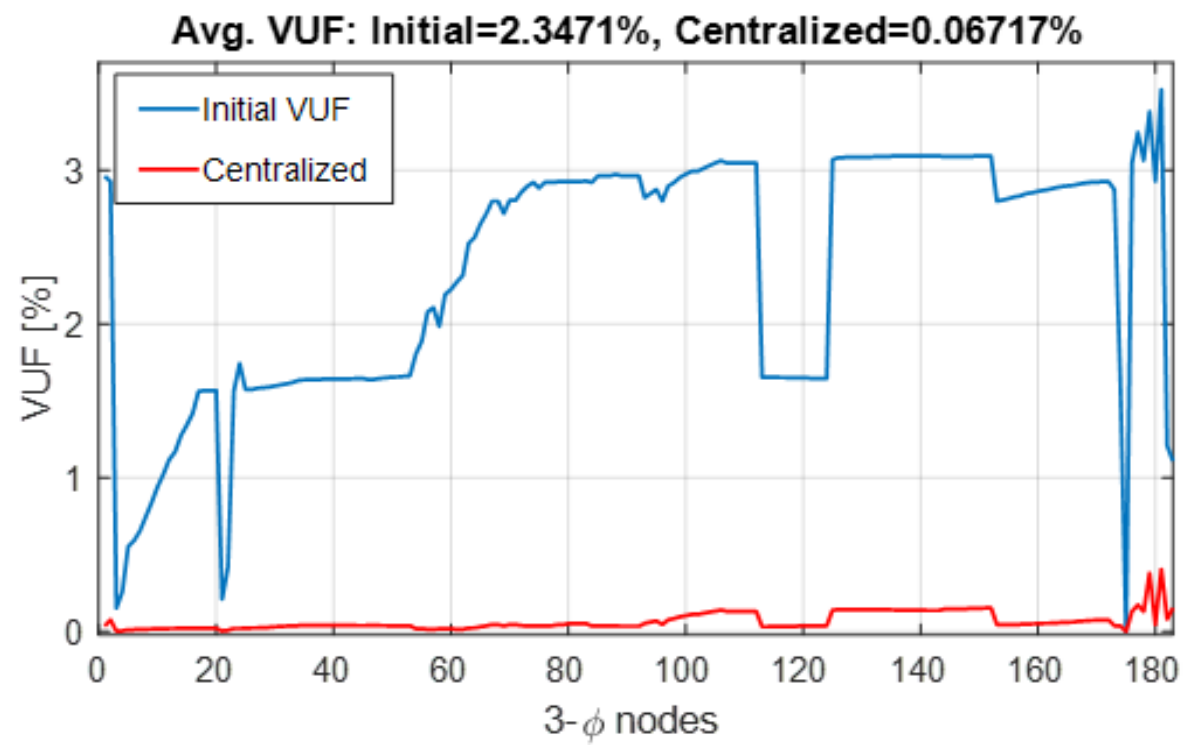

Figure 7: Minimize unbalance at all three phase buses.

We also tested the performance of the distributed controller when the load and PV generation are time-varying, as depicted in Figure 8 on the following page. The 
measurements of voltage and apparent power are taken every 2 seconds. Control signals are issued at the same rate. For this simulation, we assume no communication delay. The inverters respond directly after they receive the control signals, which is reasonable since the inverters could respond within milliseconds. Figure 9 on the following page shows the initial VUF and final VUF of the critical bus after using the distributed controller from sunrise to sunset. The distributed controller is able to significantly reduce the unbalance for the entire day despite time-varying load and PV generation, except around noon. This is because the PV real power generation is high around noon, so we do not have enough reactive power capacity to perfectly eliminate the unbalance.

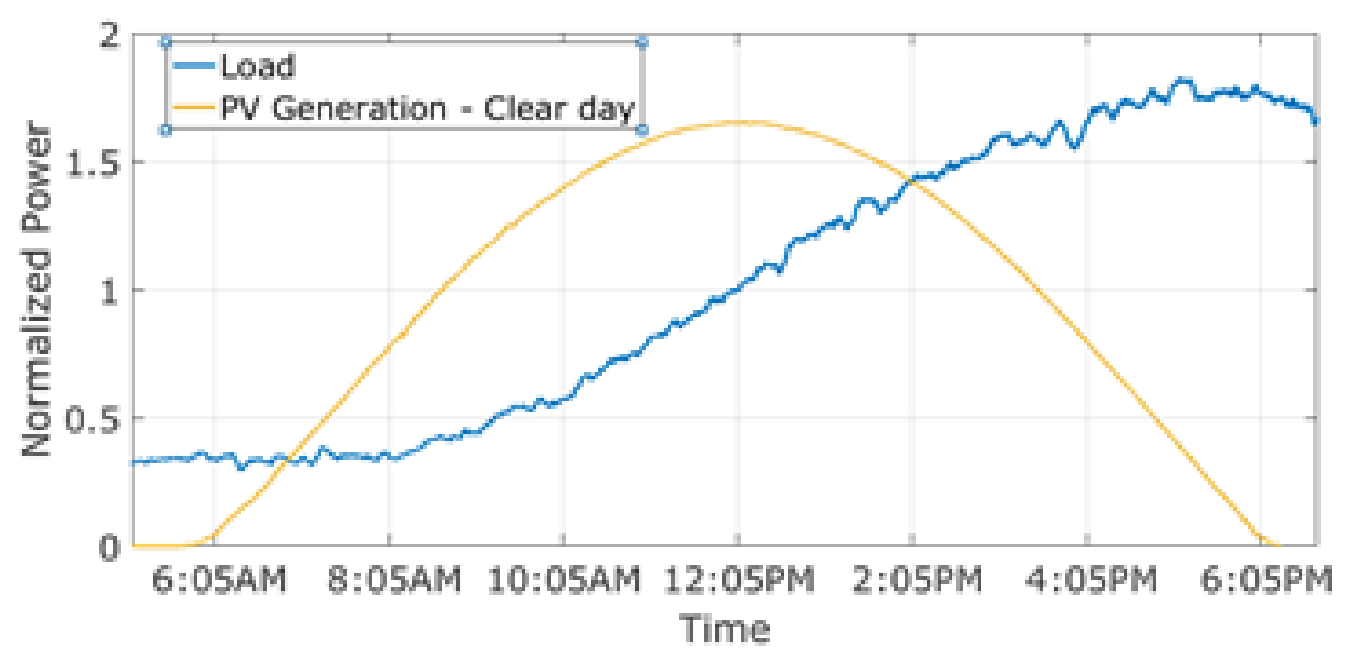

Figure 8: Normalized real power generation of PV systems and real power consumption of loads. The measurement interval is two seconds.

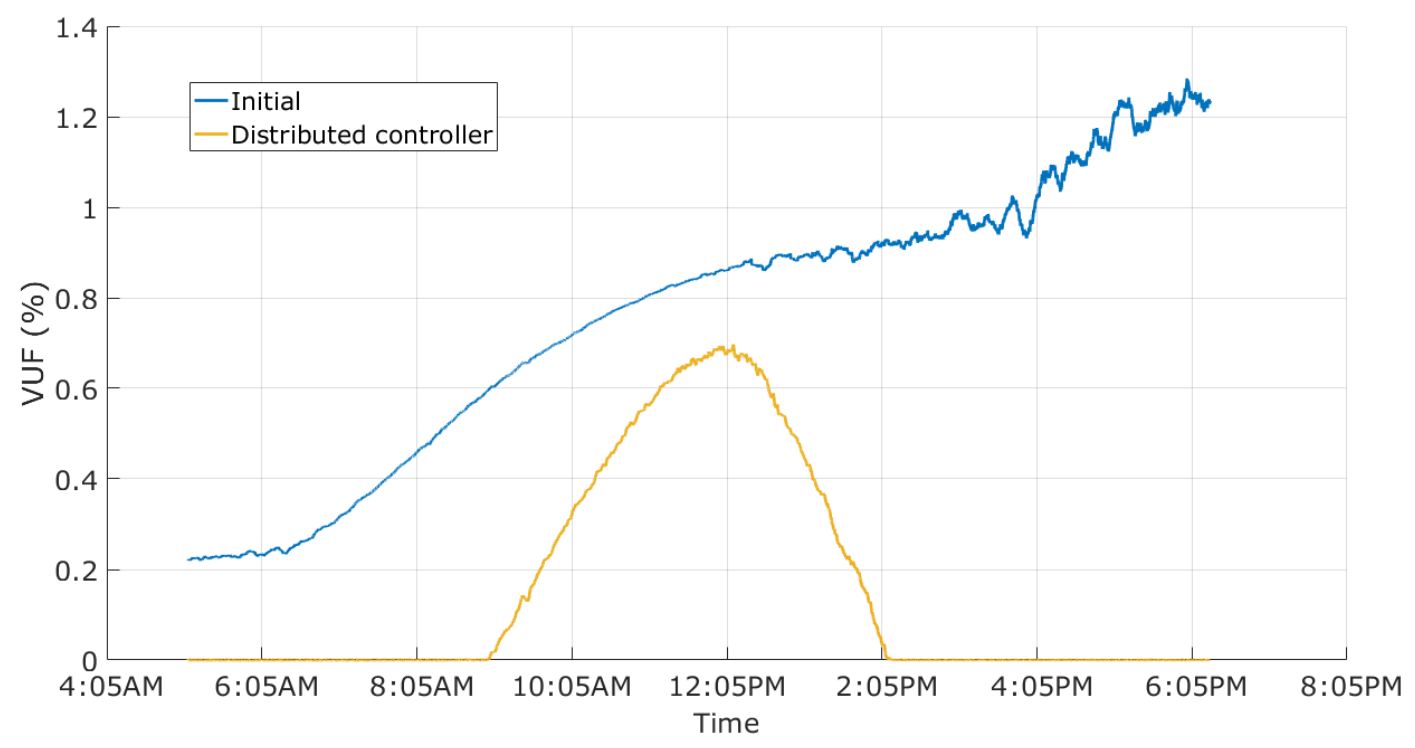

Figure 9: The VUF for the critical bus before and after using the distributed controller. The controller is triggered every two seconds. 
In addition to time-varying load demands and PV generator outputs, practical controller implementations require the ability to handle delayed communications and inaccurate measurements. For example, communication delay times that are longer than the rate of the controller action may result in over-response, which could worsen the unbalance. The project team developed variants of the distributed and grouped controllers to address these practical challenges. This section summarizes these variants. Further details regarding the project team's investigation of the impacts of these practical challenges on the performance of the distributed controller and mitigating strategies are available in [5]. In the original distributed controller design, the reactive power commands sent by the controller were the total quantity of reactive power that PV system should provide. The controller used the previous commands to compute the new commands. However, when PVs reach their reactive power limits, the PV systems cannot inject as much reactive power as commanded. Assuming the PV systems do not report their actual injections back to the operator, the operator does not know the mismatch between the command and the action. This can lead to divergence of the controller. The project team has proposed a command strategy that uses the change in the reactive power injection that PV system should provide. Case studies demonstrate that the new command strategy works better when PVs encounter reactive power limits.

Both the error and noise in the voltage and current measurements will lead to error in the estimate of the downstream power demands, and, as a result, we will obtain inaccurate reactive power injections that may increase unbalance. A number of case studies described in [5] suggest that the errors and noise do not have a large impact on the distributed controller's performance.

Communication delays may result in over-response which could worsen the unbalance. In [5], we propose two strategies to reduce the impact of communication delays. One strategy is to slow down the commands by only sending updates when the change of VUF with respect to the previous time is larger than a threshold. The second strategy is to add a proportional gain to the controller. The gain can either be constant or time varying. Case studies show that the distributed controller is capable of effectively mitigating voltage unbalance with the proposed strategies despite the presence of communication delays.

\section{Controller Implementations in the Open Modeling Framework:}

The project team has developed a new "phaseBalance" module for NRECA's Open Modeling Framework (omf.coop) that focuses on issues related to phase unbalance. Given utility inputs, the phaseBalance model simulates the consequences of a decentralized controller or constant inverter setting. The model displays three cases:

- "Base": a simulation which removes solar from the system.

- "Solar": a simulation when solar is operating at a maximum. 
- "Controlled": the selected strategy at managing unbalance.

Our model takes one time step, capturing details which can then be used to calculate monetary consequences and equipment damage. We also allow users to simulate the consequences of a constant inverter setting.

We provide output that tabulates the three cases' monetary effects, including energy cost, energy revenue, power factor penalties, and motor damage. Furthermore, by leveraging prior research from DOE EERE [10], we estimated how unbalance affected the motor lifetime. The interface provides easy sorting and searching and allows for straightforward application to general utility system models.

The phaseBalance module is also easily adaptable as a software resource via the opensource community, allowing utility engineers to customize the tool as required. For those who want to look more deeply into how the results were calculated or are interested in applying their own tests to their altered files, we return all available data to the user.

To illustrate the phaseBalance package and its interface, Figure 10 below provides the results of applying constant VARs to one of our test feeders.

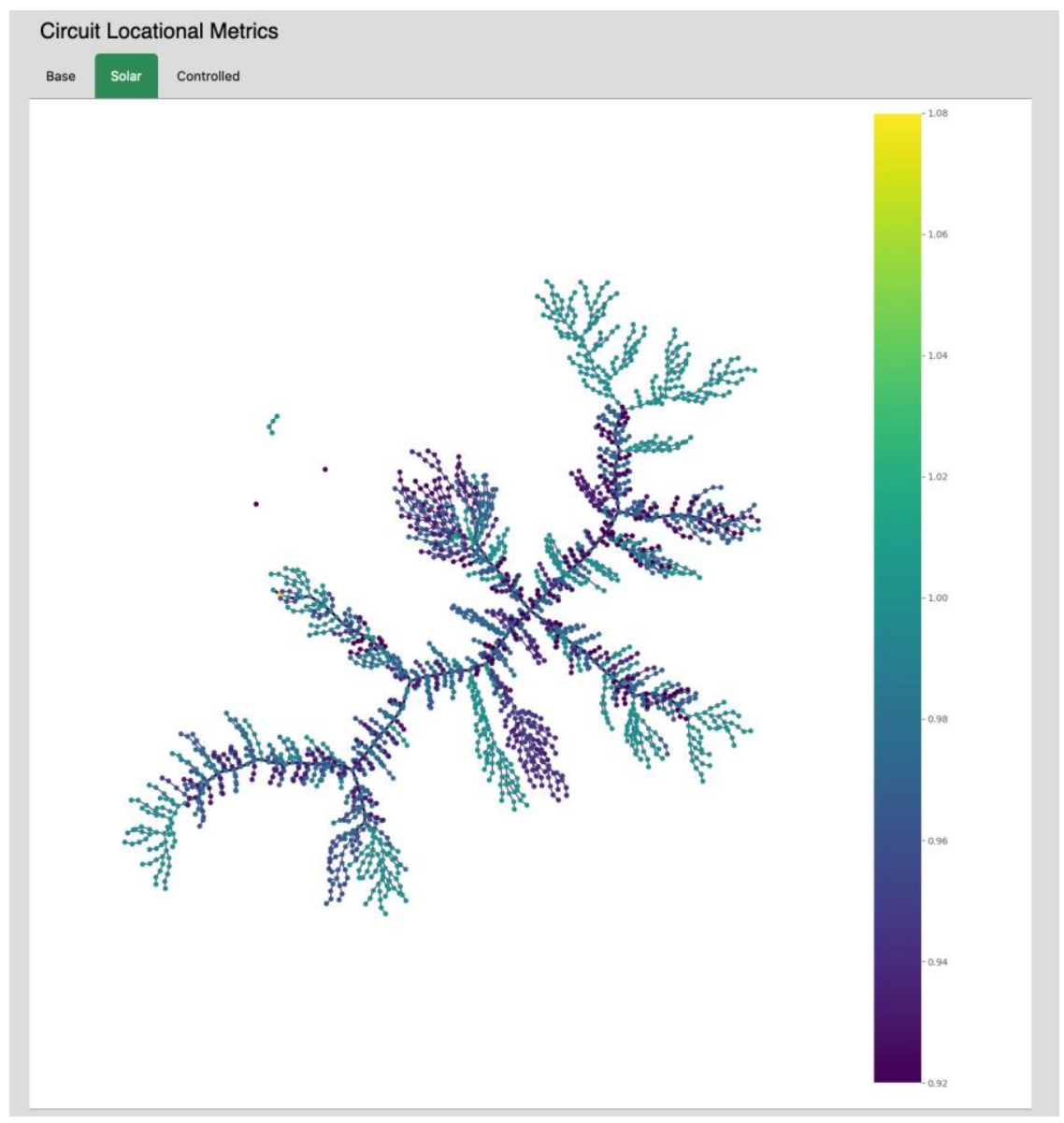


Feeder Power Summary

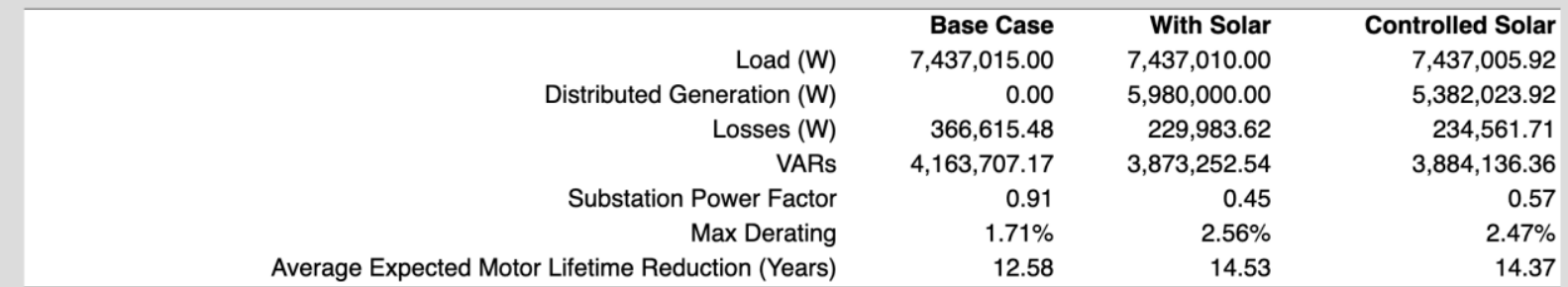

Financial Summary

\begin{tabular}{rrrr} 
& Base Case & \multicolumn{1}{c}{ With Solar } & Controlled Solar \\
Energy Cost & $-\$ 223,110.45$ & $-\$ 223,110.30$ & $-\$ 223,110.18$ \\
Energy Revenue & $\$ 371,850.75$ & $\$ 192,450.50$ & $-\$ 210,389.58$ \\
PF Penalty & $-\$ 50,000.00$ & $-\$ 50,000.00$ & $-\$ 50,000.00$ \\
Motor Damage & $-\$ 0.00$ & $-\$ 306,000,000.00$ & $-\$ 276,000,000.00$
\end{tabular}

Inverter Power Outputs

Search:

Uncontrolled Solar

Controlled Solar

\begin{tabular}{|c|c|c|c|c|c|c|}
\hline Name ${ }^{\wedge}$ & $\begin{array}{r}A B \\
\text { (VA) }\end{array}$ & $\begin{array}{l}\text { BC } \\
\text { (VA) }\end{array}$ & $\begin{array}{c}A C \\
\text { (VA) }\end{array}$ & $A B(V A)$ & $B C$ (VA) & AC (VA) \\
\hline test_solar_inverter_1 & $10000-0 j$ & $-0+0 \mathrm{j}$ & $-0+0 \mathrm{j}$ & $9000.04-0.898944 j$ & $-0+0 j$ & $-0+0 j$ \\
\hline test_solar_inverter_10 & $10000-0 j$ & $-0+0 \mathrm{j}$ & $-0+0 j$ & $9000.04-0.898944 j$ & $-0+0 j$ & $-0+0 j$ \\
\hline test_solar_inverter_100 & $-0+0 j$ & $-0+0 j$ & $10000-0 \mathrm{j}$ & $-0+0 j$ & $-0+0 j$ & $9000.04-0.898944 j$ \\
\hline test_solar_inverter_101 & $10000-0 \mathrm{j}$ & $-0+0 j$ & $-0+0 j$ & $9000.04-0.898944 j$ & $-0+0 j$ & $-0+0 j$ \\
\hline
\end{tabular}

Three Phase Motor Loads Voltage and Imbalance

Base

\begin{tabular}{|c|c|c|c|c|c|c|c|c|}
\hline \multirow[b]{2}{*}{ Name ${ }^{\Delta}$} & \multirow[b]{2}{*}{ Total kW } & \multirow[b]{2}{*}{$\begin{array}{l}\text { Total } \\
\text { VARs }\end{array}$} & \multirow[b]{2}{*}{$A(V)$} & \multirow[b]{2}{*}{$B(V)$} & \multirow[b]{2}{*}{$C(V)$} & \multicolumn{3}{|c|}{ Search: } \\
\hline & & & & & & Unbalance & $\begin{array}{r}\text { Motor } \\
\text { Derating }\end{array}$ & $\begin{array}{r}\text { Expected } \\
\text { Motor } \\
\text { Lifetime } \\
\text { Reduction } \\
\text { (Years) }\end{array}$ \\
\hline R1-12-47-1_load_11 & $27,251.01$ & $10,638.45$ & 262.70 & 252.34 & 245.47 & 2.36 & 1.71 & 16.00 \\
\hline R1-12-47-1_load_19 & $43,110.30$ & $16,829.70$ & 269.38 & 265.19 & 263.20 & 0.79 & 0.42 & 8.44 \\
\hline R1-12-47-1_load_20 & $32,165.10$ & $12,556.86$ & 262.58 & 258.94 & 257.20 & 0.72 & 0.38 & 7.86 \\
\hline R1-12-47-1_load_4 & $25,017.30$ & $9,766.47$ & 263.69 & 253.38 & 246.54 & 2.33 & 1.68 & 15.92 \\
\hline
\end{tabular}

Figure 10: The phaseBalance model created for the NRECA Open Modeling Framework (omf.coop).

\section{Application to NRECA test cases:}

To demonstrate their usefulness on practical test cases, we applied our controllers to NRECA feeders. Here, we show the comparison of the controllers' performance on an illustrative feeder from "Northeast Oklahoma EC", which has 1053 buses and 1397 triplex buses. The critical bus is far away from the substation and has a motor load which 
experiences significant unbalance. For this case, the penetration of PV is around $85 \%$. Figure 11(a) below compares the centralized controller and the distributed controller when mitigating the unbalance at the critical bus. The initial VUF at the critical bus is $2.27 \%$, which violates the $2 \%$ IEC standard. The VUFs achieved by the centralized and distributed controllers are $\mathbf{0 . 0 0 1 \%}$ and $\mathbf{0 . 2 9 \%}$, respectively. Figure 11 (b) on the following page shows the case when we want to improve the unbalance at all three-phase buses in the feeder. The initial average VUF of the feeder is $1.28 \%$ and the optimal average

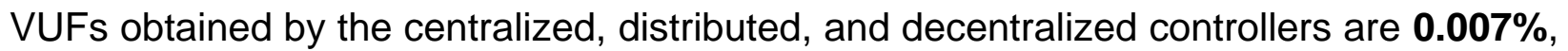
$0.14 \%$ and $0.17 \%$, respectively.

In Table 2 below, we calculate the expected dollar savings from motor life increases due to this unbalance reduction. For each motor on the circuit, we calculate the additional years of winding life that are expected from the reduction based on unbalance impacts on winding life from [10]. We assume a motor cost of $\$ 2,000 / \mathrm{kVA}$ (based on a survey of motor pricing collected from the internet), and we further reduce the savings by assuming a conservative duty cycle for each motor of $20 \%$. The total expected savings in motor lifetime for this substation is $\$ 2,315$.

\begin{tabular}{|l|r|r|r|r|r|r|r|r|r|r|}
\hline $\begin{array}{l}\text { Motor } \\
\text { ID }\end{array}$ & kVA & \multicolumn{1}{|c|}{ Unbal. } & $\begin{array}{c}\text { Motor } \\
\text { Derate }\end{array}$ & $\begin{array}{c}\text { Life } \\
\text { Red. } \\
\text { (Years) }\end{array}$ & $\begin{array}{c}\text { Control } \\
\text { Red. }\end{array}$ & $\begin{array}{c}\text { Years } \\
\text { Saved }\end{array}$ & $\begin{array}{c}\text { Perc } \\
\text { Life }\end{array}$ & Price & $\begin{array}{c}\text { Savings } \\
\mathbf{( \$ )}\end{array}$ & $\begin{array}{c}\text { Duty } \\
\text { Cycle } \\
\text { Adj. } \\
\mathbf{( \$ )}\end{array}$ \\
\hline load_7 & 103.88 & 2.79 & 2.18 & 17.02 & 6.9782 & 10.0418 & 0.50 & 6,960 & 3,495 & 699 \\
\hline load_5 & 90.98 & 3.04 & 2.48 & 17.49 & 7.1709 & 10.3191 & 0.52 & 6,096 & 3,145 & 629 \\
\hline load_6 & 47.35 & 2.99 & 2.41 & 17.4 & 7.134 & 10.266 & 0.51 & 3,173 & 1,629 & 326 \\
\hline load_19 & 43.11 & 1.06 & 0.59 & 10.35 & 4.2435 & 6.1065 & 0.31 & 2,888 & 882 & 176 \\
\hline load_20 & 32.17 & 0.95 & 0.52 & 9.58 & 3.9278 & 5.6522 & 0.28 & 2,155 & 609 & 122 \\
\hline load_11 & 27.25 & 3.11 & 2.56 & 17.6 & 7.216 & 10.384 & 0.52 & 1,826 & 948 & 190 \\
\hline load_4 & 25.02 & 3.08 & 2.53 & 17.56 & 7.1996 & 10.3604 & 0.52 & 1,676 & 868 & 174 \\
\hline TOTAL & & & & & & & & & & $\mathbf{2 , 3 1 5}$ \\
\hline
\end{tabular}

Table 2: Expected savings from motor winding life increase

For this test case, the centralized controller achieves lower voltage unbalance but requires more computation (approximately 15 minutes to solve the three-phase optimal power flow) as well as an accurate distribution system model and access to measurements of all load consumption and PV generation. Conversely, while the distributed controller still needs communication between PV systems and access to local measurements, this controller does not require a distribution system model and has faster computation times (approximately 10 seconds). For the decentralized controller, no busto-bus communication is required since each bus tries to mitigate its own unbalance. However, in most cases, the individual buses do not have PV generators connected to all three phases so the controller cannot inject adequate three-phase reactive power compensations. Furthermore, since the decentralized controller can only control PV systems at measured buses, the amount of controllable PV systems will be small, and 
the decentralized controller thus obtains the least improvement in voltage unbalance among the developed controllers.

Table 3 on the following page qualitatively summarizes the advantages and limitations of each controller. Table 4 then provides a quantitative summary of the results for this test case. Moreover, reference [7] provides additional details regarding comparisons of the Steinmetz-based controllers to model-free controllers.

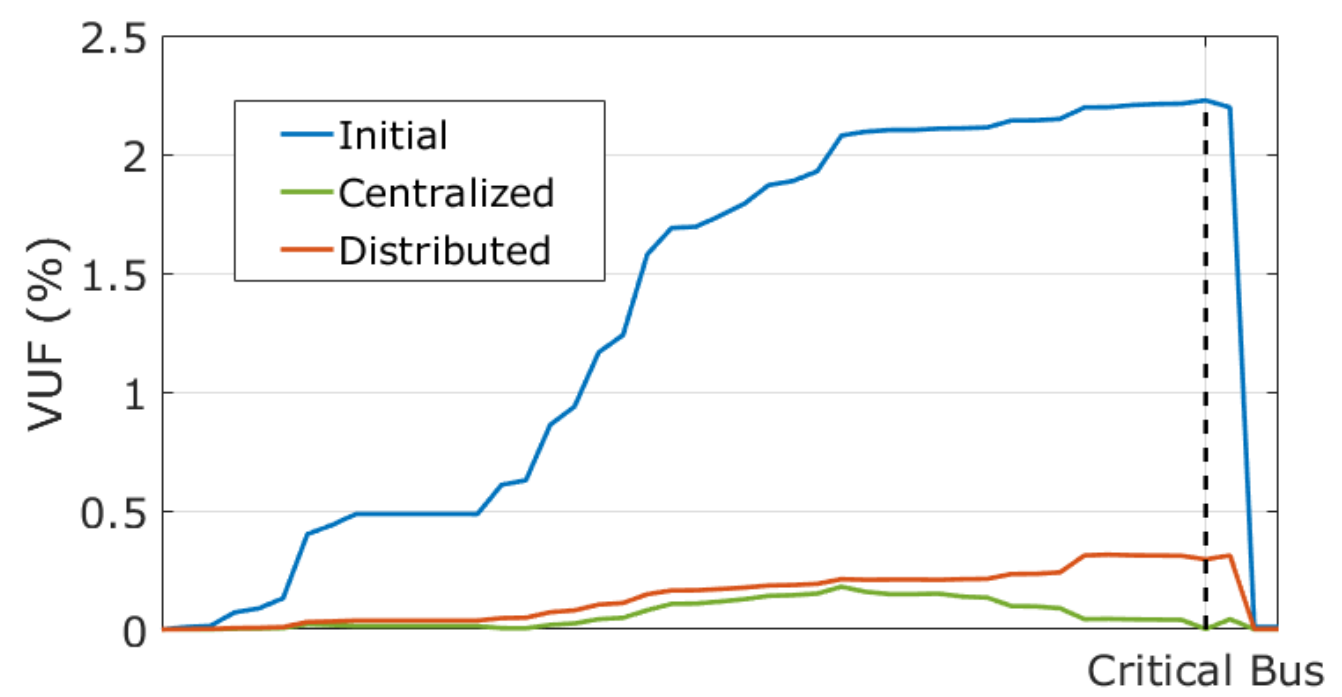

Three-phase Bus

(a) Minimize unbalance at the critical bus.

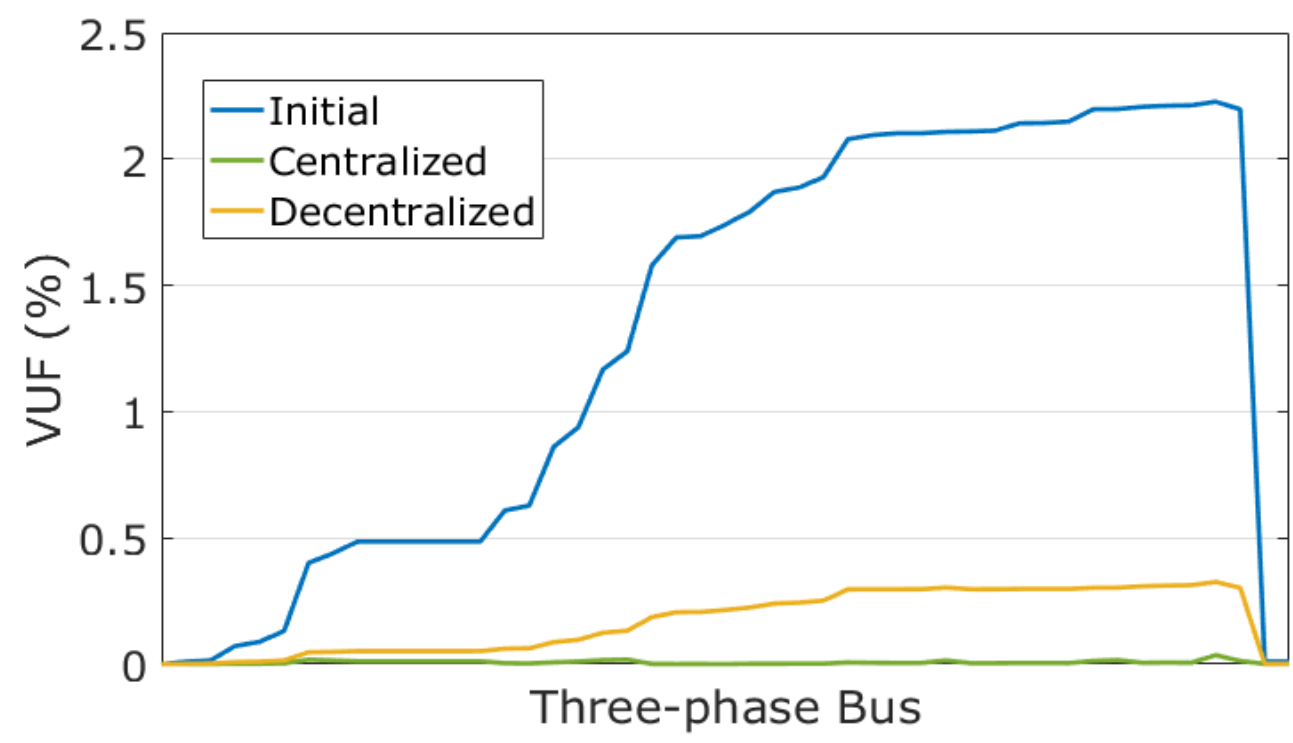

(b) Minimize unbalance at all three-phase buses.

Figure 11: Comparison of controller performance for NRECA test case "Northeast Oklahoma EC" for two different objective functions. 


\begin{tabular}{|c|c|c|}
\hline Controller & Advantages & Disadvantages \\
\hline Centralized & $\begin{array}{l}\text { - Provides the best possible } \\
\text { solution. } \\
\text { - All operational and physical } \\
\text { constraints of the system are } \\
\text { considered. } \\
\text { - Ability to minimize network } \\
\text { losses in addition to } \\
\text { mitigating voltage unbalance } \\
\text { using multiple definitions. }\end{array}$ & $\begin{array}{l}\text { - Computationally expensive. } \\
\text { - Requires communication, } \\
\text { accurate model of entire } \\
\text { distribution network, and } \\
\text { frequent measurements of } \\
\text { load and PV generation. }\end{array}$ \\
\hline $\begin{array}{l}\text { Distributed } \\
\text { and Grouped }\end{array}$ & $\begin{array}{l}\text { - Converges to the solution } \\
\text { very quickly with local } \\
\text { measurements of the critical } \\
\text { bus and low computational } \\
\text { requirements. } \\
\text { - Achieves unbalance } \\
\text { improvements that are similar } \\
\text { to the centralized controller } \\
\text { when balancing node is close } \\
\text { to substation. } \\
\text { - Ability to incorporate system } \\
\text { changes (load and PV } \\
\text { generation variation, } \\
\text { regulator tap changes, etc.). }\end{array}$ & $\begin{array}{l}\text { - Requires a one-way } \\
\text { communication network. } \\
\text { - Reduced unbalance } \\
\text { improvement when } \\
\text { balancing node at end of } \\
\text { feeder. } \\
\text { - Solution might violate } \\
\text { system constraints, e.g., } \\
\text { voltage magnitude limits, } \\
\text { due to limited knowledge of } \\
\text { the system. } \\
\text { - Only one unbalance } \\
\text { objective can be improved at } \\
\text { a time. }\end{array}$ \\
\hline Decentralized & $\begin{array}{l}\text { - No bus-to-bus } \\
\text { communication is required. } \\
\text { - Converges to the solution } \\
\text { very quickly with low } \\
\text { computational requirements. } \\
\text { - Ability to incorporate system } \\
\text { changes (load and PV } \\
\text { generation variation, } \\
\text { regulator tap changes, etc.). }\end{array}$ & $\begin{array}{l}\text { Least improvement in } \\
\text { voltage unbalance. } \\
\text { - Solution might violate } \\
\text { system constraints, e.g., } \\
\text { voltage magnitude limits, } \\
\text { due to limited knowledge of } \\
\text { the system. } \\
\text { - Only one unbalance } \\
\text { objective can be improved at } \\
\text { a time. }\end{array}$ \\
\hline
\end{tabular}

Table 3: Qualitative summary of the controllers' advantages and disadvantages. 


\begin{tabular}{|c|c|c|c|c|}
\hline & $\begin{array}{c}\text { Benchmark Case } \\
\text { (Unity Power Factor, } \\
\text { No Control) }\end{array}$ & $\begin{array}{c}\text { Centralized } \\
\text { Controller }\end{array}$ & $\begin{array}{c}\text { Distributed } \\
\text { Controller }\end{array}$ & $\begin{array}{c}\text { Decentralized } \\
\text { Controller }\end{array}$ \\
\hline $\begin{array}{c}\text { Unbalance at } \\
\text { the critical } \\
\text { bus }\end{array}$ & $2.27 \%$ & $0.001 \%$ & $0.29 \%$ & $\mathrm{~N} / \mathrm{A}$ \\
\hline $\begin{array}{c}\text { Average } \\
\text { unbalance at } \\
\text { all buses }\end{array}$ & $1.28 \%$ & $0.007 \%$ & $0.14 \%$ & $0.17 \%$ \\
\hline Solution Time & $\mathrm{N} / \mathrm{A}$ & 15 minutes & 10 seconds & 10 seconds \\
\hline Iterations & $\mathrm{N} / \mathrm{A}$ & 1 & 5 & 5 \\
\hline
\end{tabular}

Table 4: Quantitative summary of the controllers' performance for the NRECA test case "Northeast Oklahoma EC" (1053 buses and 1397 triplex buses).

\section{Theoretical Developments - Convergence:}

The developed Steinmetz control schemes are iterative processes in the sense that the reactive power injections are successively updated based on the response of the power flow to the previous value of the reactive power injections. As with any iterative process, the question of convergence is very important. The project team has established theoretical convergence guarantees for Steinmetz-based decentralized controllers that consider the phase unbalance at multiple critical buses. Providing such convergence ensures the applicability of the developed controllers to systems with uncertain parameters and perturbations. The project team has studied both the scenario of synchronized control actions and the scenario with time-delays in the measurements and implementations. In generic cases, the controllers can have different time-delays. In the analysis, we adopt a linear multiphase power flow model derived from a fixed-point form of the power flow equations [27]. We formulate an optimization program that computes an accurate approximation for the final converged point, which results in a high-fidelity linear power flow model. Hence, the Steinmetz-based controllers can be written explicitly as a quadratic mapping of the reactive power injections from the previous step to the next step. We then apply Banach fixed-point theory to certify the stability of the controllers. 
The convergence results can be interpreted in two ways. Given the network topology and system parameters such as line impedances and nominal loading conditions, we can certify an operating region where the decentralized and distributed controllers converge to a unique operating point. On the other hand, given the network topology and a prescribed convergence region, we can provide conditions that system parameters must satisfy in order to guarantee convergence of the decentralized controller. Further details regarding the convergence guarantees developed in this project are available in [8].

\section{Theoretical Developments - Robustness:}

Uncertain power injections from fluctuating renewable generation and load consumption may affect the controllers' performance with respect to mitigating phase unbalances while satisfying other grid requirements. Hence, to ensure secure grid control and operations against these uncertainties, the project team has developed the theory for a robust formulation of the centralized controller design such that the phase unbalance requirement is guaranteed to be satisfied under the influence of the uncertainty. To achieve this objective, we have extended so-called power flow "solvability conditions" to consider phase unbalance.

In general power flow analysis, a solvability condition is defined as the requirements on the system control variables (real power injections and voltage magnitudes at PV buses and real and reactive power injections at $P Q$ buses) such that the AC power flow equations admit at least one feasible solution (voltage phasors at all buses). We have extended existing solvability conditions from [28] by enforcing an additional phase unbalance requirement on these feasible solutions. We call the result a "balancibility" condition. In other words, a balancibility condition quantifies a secure power injection region such that all the feasible solutions satisfy the phase unbalance requirements. To derive the balancibility conditions, we have modified existing solvability conditions and optimally matched them to all of the phase unbalance definitions identified throughout the project. The resulting balancibilitiy conditions, which are based on fixed-point theorems and different optimization techniques, provide various theoretical guarantees on the existence and uniqueness of balanced power flow solutions. Initial simulation results demonstrate the balancibility conditions' ability to link the phase balance requirements with uncertain power injections to provide the aforementioned guarantees.

The balancibility conditions provide the key theory required to compute operating points that are robust to uncertain power injections. Meanwhile, these conditions also greatly simplify the power flow analysis in distribution networks and provide an efficient approach to quantify phase unbalance under uncertainties. 


\section{Significant Accomplishments and Conclusions:}

This project has completed all milestones in developing, testing, and comparing controllers that are capable of effectively mitigating phase unbalance in systems with high penetrations of distributed solar PV generators. The developed controllers are applicable to systems with a range of communication and measurement infrastructures as well as different levels of PV penetration. Moreover, the project has addressed both practical issues related to communication delays, measurement noise, etc. as well as theoretical issues related to convergence and robustness guarantees. Testing on real distribution systems from NRECA member co-ops demonstrates the controllers' ability to significantly reduce phase unbalance from unacceptable levels in the uncontrolled system to be well within required limits after application of the controllers.

\section{Inventions, Patents, Publications, and Other Results:}

Project results were published in both peer-reviewed journals and conferences as well as communicated to industry via outreach to NRECA member co-ops.

[1] M. Yao, I.A. Hiskens, and J.L. Mathieu, "Applying Steinmetz Circuit Design to Mitigate Voltage Unbalance Using Distributed Solar PV," IEEE Milan PowerTech, Milan, Italy, June 2019.

[2] K. Girigoudar, D.K. Molzahn, and L.A. Roald, "On the Relationships Among Different Voltage Unbalance Definitions," North American Power Symposium (NAPS), Wichita, Kansas, October 2019.

[3] D. Pinney and K. McElwee, "A Planning Model for Improving Phase Balance Through Inverter Reactive Power Control," NRECA Business and Technology Advisory Newsletter, Oct. 2019.

[4] K. Girigoudar and L.A. Roald, "On the Impact of Different Voltage Unbalance Metrics in Distribution System Optimization," Electric Power Systems Research, vol. 189, no. 106656, December 2020. Presented at the 21st Power Systems Computation Conference (PSCC), Porto, Portugal, June 2020.

[5] M. Yao and J.L. Mathieu, "Overcoming the Practical Challenges of Applying Steinmetz Circuit Design to Mitigate Voltage Unbalance Using Distributed Solar PV," Electric Power Systems Research, vol. 188, no. 106563, December 2020. Presented at the 21st Power Systems Computation Conference (PSCC), June 2020.

[6] B. Li, B. Cui, F. Qiu, and D.K. Molzahn, "Balancibility: Existence and Uniqueness of Power Flow Solutions under Voltage Balance Requirements," Electric Power Systems Research, vol. 190, no. 106542, January 2021. Presented at the 21st Power Systems Computation Conference (PSCC), June 2020. 
[7] M. Yao, I.A. Hiskens, and J.L. Mathieu, "Mitigating Voltage Unbalance Using Distributed Solar Photovoltaic Inverters," IEEE Transactions on Power Systems, vol. 36, no. 3, pp. 2642-2651, May 2021.

[8] S. Geng and I.A. Hiskens, "Convergence of Distributed Steinmetz Control for Phase Balancing of Distribution Networks," submitted to IEEE Transactions on Power Systems.

[9] M. Yao, "Using Distributed Energy Resources to Improve Power System Stability and Voltage Unbalance," PhD dissertation, University of Michigan Department of Electrical Engineering and Computer Science, August 2020.

\section{Path Forward:}

The project's simulations on real systems have demonstrated the potential value of the developed controllers. Next steps regarding further theoretical and simulation-based efforts are:

- Theoretical analyses and improvements to existing methods for incorporating communication and computation delays.

- Additional study of tradeoffs among different control objectives (e.g., negative sequence voltage improvements versus neutral currents).

- Analyses regarding interactions with other DER controllers, such as energy storage devices, demand response schemes, electric vehicle charging programs, etc.

- Development of online centralized controllers to improve speed and robustness by building on work surveyed in [29].

- Assessment regarding the prioritization of various functionalities for smart inverters (e.g., the relative importance of control efforts intended to maintain appropriate voltage magnitudes versus phase unbalance mitigation).

Other appropriate next steps are field demonstrations of the developed controllers in order to validate the project's simulation results in practical settings. A possible venue for these field demonstrations is NRECA's ongoing Inverter Control Demonstration Study, which is currently testing communication and interoperability for IEEE 1547 voltage regulation and ride-through capabilities with two member utilities: Black River in South Carolina and Wood County in Texas. The communication, measurement, and control infrastructure present at these sites along with the NRECA's experience in IEEE 1547 testing make these sites well suited for field demonstrations of the phase unbalance mitigating controllers. 


\section{References:}

This section provides additional references beyond the project publications given above. [10] G.A. McCoy and J.G. Douglass, Premium efficiency motor selection and application guide-A handbook for industry, No. DOE/GO-102014-4107, Washington State University Energy Program, 2014.

[11] Department of Energy, "Stopping a costly leak: The effects of unbalanced voltage on the life and efficiency of three-phase electric motors," Energy Matters, Winter 2005.

[12] C.H. Castro, J.B. Bunch, T.M. Topka, "Generalized algorithms for distribution feeder deployment and sectionalizing," IEEE Transactions on Power Apparatus and Systems, vol. PAS-99, no. 2, March 1980.

[13] D. R. Smith, H. R. Braunstein, J. D. Borst, "Voltage unbalance in 3- and 4-wire delta secondary systems," IEEE Transactions on Power Delivery, vol. 3, no. 2, pp. 733-741, April 1988.

[14] A. von Jouanne, B. Banerjee, "Assessment of voltage unbalance," IEEE Transactions on Power Delivery, vol. 16, no. 4, pp. 782-790, October 2001.

[15] D.A. Rendusara, A. Von Jouanne, P.N. Enjeti, D.A. Paice, "Design considerations for 12-pulse diode rectifier systems operating under voltage unbalance and pre-existing voltage distortion with some corrective measures," IEEE Transactions on Industrial Applications, vol. 32, no. 6, November/December 1996.

[16] J.-H. Chen, W.-J. Lee, M.-S. Chen, "Using a static VAr compensator to balance a distribution system," 31st IEEE Industry Applications Society Annual Meeting (IAS), pp. 2321-2326, San Diego, CA, October 1996.

[17] S. Kadam and B. Bletterie, "Balancing the grid with single-phase PVinstallations," 26th IEEE International Symposium on Industrial Electronics (ISIE), Edinburgh, UK, pp. 63-69, June 2017.

[18] S. Sun, B. Liang, M. Dong, J.A. Taylor, "Phase balancing using energy storage in power grids under uncertainty," IEEE Transactions on Power Systems, vol. 31, no. 5, pp. 3891-3903, September 2016.

[19] ABB, "Multiple SVC installations for traction load balancing in Central Queensland," https://library.e.abb.com/public/9d4eec9d07475dd1c1256fda003b4cfc/A02-

0134E_Multiple\%20SVC_LR.pdf

[20] L. Neukirchner, P. Gorbe, A. Magyar, "Voltage unbalance reduction in the domestic distribution area using asymmetric inverters," Journal of Cleaner Production, vol. 142, no. 4, pp. 1710-1720, January 2017. 
[21] F. Shahnia, A. Ghosh, G. Ledwich, F. Zare, "Voltage unbalance improvement in low voltage residential feeders with rooftop PVs using custom power devices," International Journal of Electrical Power \& Energy Systems, vol. 55, pp. 362-377, February 2014.

[22] S. Deshmukh, B. Natarajan, A. Pahwa, "Voltage/VAR control in distribution networks via reactive power injection through distributed generators," IEEE Transactions on Smart Grid, vol. 3, no. 3, pp. 1226-1234, September 2012.

[23] S. Weckx, C. Gonzalez, and J. Driesen, "Reducing grid losses and voltage unbalance with PV inverters," IEEE Power and Energy Society General Meeting, National Harbor, MD, July 2014.

[24] C. Zhong, E. Dall'Anese, and S.H. Low, "Convex relaxation of OPF in multiphase radial networks with delta connections," 10th Bulk Power Systems Dynamics and Control Symposium (IREP), Porto, Portugal, August 2017.

[25] C.P. Steinmetz, Theory and calculations of electrical apparatus, McGraw-Hill Incorporated, 1917.

[26] O. Jordi, L. Sainz, and M. Chindris, "Steinmetz system design under unbalanced conditions," European Transactions on Electrical Power, vol. 12, no. 4, pp. 283-290, July/August 2002.

[27] A. Bernstein, C. Wang, E. Dall'Anese, J. Le Boudec and C. Zhao, "Load flow in multiphase distribution networks: Existence, uniqueness, non-singularity and linear models," IEEE Transactions on Power Systems, vol. 33, no. 6, pp. 5832-5843, November 2018.

[28] B. Cui and X.A. Sun, "Solvability of power flow equations through existence and uniqueness of complex fixed point," arXiv:1904:08855, April 2019.

[29] D.K. Molzahn, F. Dörfler, H. Sandberg, S.H. Low, S. Chakrabarti, R. Baldick, and J. Lavaei, "A survey of distributed optimization and control algorithms for electric power systems," IEEE Transactions on Smart Grid, vol. 8, no. 6, pp. 2941-2962, November 2017. 


\section{Argonne}

Argonne National Laboratory

9700 South Cass Avenue

Lemont, IL 60439

www.anl.gov 